\title{
Impact of the 1998 World Health Organization/ International Society of Urological Pathology classification system for urothelial neoplasms of the kidney
}

\author{
Elizabeth M Genega ${ }^{1}$, Malathy Kapali ${ }^{1}$, Marta Torres-Quinones ${ }^{1}$, William C Huang ${ }^{2}$, \\ Jill S Knauss ${ }^{3}$, Li-Ping Wang ${ }^{1}$, Puthiyaveettil N Raghunath ${ }^{1}$, Christopher Kozlowski ${ }^{1}$, \\ Stanley Bruce Malkowicz ${ }^{4}$ and John E Tomaszewski ${ }^{1}$ \\ ${ }^{1}$ Department of Pathology, University of Pennsylvania Medical Center, Philadelphia, PA, USA; ${ }^{2}$ Department \\ of Urology, Lahey Clinic, Burlington, MA, USA; ${ }^{3}$ Department of Epidemiology and Biostatistics and \\ ${ }^{4}$ Department of Urology, University of Pennsylvania Medical Center, Philadelphia, PA, USA
}

\begin{abstract}
The classification of urothelial neoplasms of the kidney traditionally has been similar to that of urinary bladder tumors. Several years ago, the classification of papillary urothelial neoplasms was revised. The current study focuses on the application of the 1998 World Health Organization (WHO)/International Society of Urological Pathology classification system to 102 renal pelvic urothelial neoplasms and compares it to the 1973 WHO classification scheme. In this study, all tumors were classified as urothelial carcinomas, and the majority (85\%) were papillary. Most patients with papillary tumors presented with 'superficial' disease ( $\leq$ pT1). With the 1998 system, most papillary carcinomas were high grade, and were more often invasive as compared to low-grade tumors. Only $34 \%$ were low-grade papillary tumors and, of these, most $(93 \%)$ were noninvasive. With the 1973 system, most papillary tumors were grade 2 or 3, with invasion more common in grade 3 tumors. By 1973 criteria, grade 2 tumors were a heterogeneous group; with 1998 criteria, nearly one-half were high grade and the other half low grade. The grade of papillary urothelial carcinomas with both the 1973 and 1998 grading methods was associated with stage $(P=0.001)$. Our study reveals that papillomas and papillary urothelial neoplasms of low malignant potential are uncommon tumors in the kidney. Renal pelvic papillary urothelial neoplasms are most often carcinomas and are more commonly high grade than low grade. Although both the 1973 and 1998 systems showed a significant association with tumor stage, grade 2 papillary carcinomas are a heterogeneous group by 1973 criteria. The 1998 system provides useful information in that it more clearly defines a papillary tumor's grade and selects for a group of tumors, namely low-grade papillary urothelial carcinomas, for which a low likelihood of invasion can be predicted.
\end{abstract}

Modern Pathology (2005) 18, 11-18, advance online publication, 8 October 2004; doi:10.1038/modpathol.3800268

Keywords: kidney; papillary urothelial carcinoma; urothelial neoplasm; World Health Organization; International Society of Urological Pathology

Urothelial neoplasms of the kidney are, by most accounts, uncommon, accounting for approximately $4-10 \%$ of primary renal epithelial tumors and only $5 \%$ of all urothelial tumors. ${ }^{1-4}$ The accurate incidence of renal urothelial carcinomas in the United States is difficult to determine because reports of

Correspondence: Dr EM Genega, MD, Department of Pathology, East Campus, Beth Israel Deaconess Medical Center, 330 Brookline Avenue, Boston, MA 02215, USA.

E-mail: egenega@bidmc.harvard.edu

Received 26 March 2004; revised and accepted 12 July 2004; published online 8 October 2004 cancer statistics combine these tumors with renal cell carcinomas. ${ }^{5}$ In certain regions of the world, and in patients with certain tubulointerstitial nephritides, the incidence of urothelial neoplasms of the renal pelvis and ureter is quite high, with renal pelvic carcinoma accounting for as much as $68 \%$ of renal tumors in some series., ${ }^{4,6}$ As a result of the general scarcity of these tumors, ${ }^{7-24}$ coupled with the even lower incidence of ureteral urothelial tumors $(1 \%$ of urothelial neoplasms $),{ }^{2}$ a large proportion of published reports incorporate tumors at both sites into single studies. There have been few analyses of renal pelvic urothelial neoplasms recently in the pathology literature. 
The medical literature is replete with studies concerning bladder neoplasia, but relatively sparse regarding upper tract tumors. The scarcity of renal urothelial neoplasms and the fact that the majority of urothelial neoplasms occur in the urinary bladder have impeded analyses of upper tract tumors. Since the urothelial lining of the bladder is more readily accessible for surveillance than the urothelium of the renal pelvic/calyceal system, combined with the fact that bladder urothelial lesions are generally less radically treated at presentation, the natural behavior of urothelial neoplasms has been more thoroughly evaluated in the bladder than in the kidney. Consequently, the classification systems and grading schemes for urothelial neoplasms have been directed at the bladder. Regardless of their site of origin, however, urothelial neoplasms are virtually identical histologically. Therefore, the classification schemes for bladder urothelial neoplasms have been applied to these tumors in the kidney and along the entire urinary tract.

The classification of urothelial tumors, and in particular the classification of papillary urothelial neoplasms, has been an area of controversy. There is a lack of uniformity in definitions, reflected in the number of different classification/grading systems which have been proposed for these neoplasms. ${ }^{1,25-33}$ Until a few years ago, the 1973 World Health Organization (WHO) ${ }^{27}$ scheme appeared to be the most widely recognized and utilized. In an attempt to provide a method of categorization that more accurately reflects a tumor's biologic behavior, and to establish greater uniformity in defining urothelial lesions, the WHO/International Society of Urological Pathology (WHO/ISUP) ${ }^{32}$ issued a consensus statement in 1998 regarding the classification of urothelial lesions. This variance in opinion continued, however, as demonstrated by the issuance of a slightly different classification system the following year. ${ }^{33}$ Nevertheless, the 1998 classification system is the system that can be credited with changing the manner in which urothelial neoplasms are currently classified, as reflected in the 2004 WHO system, which has adopted the 1998 WHO/ISUP system. ${ }^{34}$ The 1998 WHO/ISUP system was applied to a series of renal urothelial neoplasms in this study, and the advantages and disadvantages of this scheme were compared to those of the 1973 WHO classification system.

\section{Materials and methods}

From the surgical pathology files, we retrieved 102 nonconsecutive total nephroureterectomies and nephron-sparing resections performed for urothelial neoplasms of the kidney at our institution from 1972 to 1997. Only cases for which all slides and/or tissue blocks were available were included in the study group. The morphologic features and pathologic stage for each tumor were evaluated by one pathologist (EMG). The type of noninvasive disease present (papillary urothelial neoplasm and urothelial carcinoma in situ) was recorded. The classification of papillary urothelial neoplasms was assessed with both the 1973 WHO and 1998 WHO/ISUP classification systems. The 1973 WHO system was modified somewhat with four tumor grade categories used (grades 1, 1-2, 2 and 3). All papillary urothelial neoplasms with low-grade cytology were reviewed by two pathologists (EMG, JET). The invasive component of the tumors was not graded because the significance of and criteria for grading invasive urothelial carcinoma are unclear. The presence of squamous, glandular and small cell/ neuroendocrine differentiation was recorded, as was the tumor growth pattern (exophytic vs endophytic). Other pathologic features documented included the presence or absence of lymphovascular and perineural invasion, tumor necrosis, an inflammatory infiltrate and lymph node metastases. Tumor stage was assessed with the 2002 American Joint Committee on Cancer staging system. ${ }^{35}$ The size of the tumors was not recorded, as this was not documented or difficult to ascertain in a significant number of cases.

Clinical status was determined by contacting the patient's primary physician if the patient was referred from an outside institution or from documentation of recent patient office visits at our institution.

For the statistical analyses, we used Cox proportional hazards regression to model all-cause mortality. Owing to the small number of disease-specific deaths, we were unable to model disease-specific mortality. As there were so few cases of all-cause mortality, only univariate survival results are presented. In order to determine the relationship between stage and other prognostic factors, we created contingency tables and used $\chi^{2}$-test to test the hypothesis of no association. Fisher's two-tailed test was used to evaluate the difference in frequency of invasion between the 1973 and 1998 grading systems. All analyses were performed using SAS Version 8.1 (SAS Institute INC., Cary, NC, USA).

\section{Results}

\section{Clinical Findings}

The study group consisted of 102 nephrouretectomies and nephron-sparing specimens from 98 patients; three patients had bilateral renal disease (one synchronous, two asynchronous). Of the 102 cases, 95 were total nephroureterectomies and seven were nephron-sparing procedures. In all, 60 men and 38 women (ratio 1.6:1) comprised the study group, and age ranged from 39 to 90 years with a mean age of 59 years. The urothelial neoplasms occurred more frequently in the left kidney (61 cases) than the right kidney (41 cases). Table 1 shows the clinical status for 74 patients $(76 \%)$ for 
whom follow-up information was available; 24 patients were lost to follow-up. Follow-up ranged from 3 to 206 months with a mean of 53 months and a median of 43 months.

\section{Pathologic Findings}

At nephrectomy, 50 cases (49\%) showed noninvasive disease only and 52 cases $(51 \%)$ had invasive disease (Table 2). A total of 70 cases (69\%) demonstrated 'superficial' disease ( $\leq \mathrm{pT} 1$ disease) and 32 cases (31\%) were pathologic stage 2 or greater. The majority of the renal urothelial tumors (87 cases, 85\%) demonstrated an exophytic papillary growth pattern at least focally; 47 cases were noninvasive tumors and 40 papillary tumors were associated with an invasive component. In all, 35 cases (34\%) had partial inverted growth. A total of 10 cases $(10 \%)$ showed either squamous or glandular differentiation (eight squamous, two glandular, all less than $10 \%$ of the tumor); four of these cases showed no greater than lamina propria invasion and six cases were $\geq \mathrm{pT} 3$. No tumor showed neuroendocrine differentiation. A total of 12 patients (12\%) had distant metastases, six patients $(6 \%)$ had regional lymph node metastasis, and two patients (2\%) developed retroperitoneal recurrence. Vascular invasion was present in 21 cases (21\%) of invasive disease; a noninvasive component was identified in 19 of the 21 cases and was high grade in all cases (either urothelial carcinoma in situ or high-grade papillary urothelial carcinoma, by 1998 criteria).

Table 1 Clinical status of patients with follow-up

Patient status

Alive, no evidence of disease

Alive with disease

Dead of disease

Dead of other causes

Dead, cause unknown

Total

Table 2 Final pathologic stage of renal urothelial neoplasms at nephrectomy

\begin{tabular}{lc}
\hline Pathologic stage (2002 AJCC) & Number of cases \\
\hline pT0 & 0 \\
PTa & $42(41 \%)$ \\
PTIS & $3(3 \%)$ \\
pTa and pTIS & $5(5 \%)$ \\
pT1 & $20(19 \%)$ \\
pT2 & $4(4 \%)$ \\
pT3 & $19(19 \%)$ \\
pT4 & $9(9 \%)$ \\
\hline
\end{tabular}

AJCC, American Joint Committee on Cancer Staging System. ${ }^{35}$

Table 3 shows the distribution of renal papillary urothelial neoplasms utilizing the 1973 WHO and 1998 WHO/ISUP classification schemes for papillary urothelial neoplasms. In this series, there were no papillomas or papillary urothelial neoplasms of low malignant potential (1973 WHO grade $1 / 3$ papillary urothelial carcinoma); all exophytic urothelial tumors were classified as papillary urothelial carcinomas. With the 1998 system, a greater number of papillary tumors were classified as high grade $(n=57)$ than low grade $(n=30)$, while most tumors were grade 2 or 3 by 1973 criteria (Figures 1 and 2).

Table 4 provides the distribution of papillary urothelial carcinomas by grade and stage. Most patients with papillary tumors $(77 \%)$ presented with low-stage disease $(\leq \mathrm{pT} 1)$. Of these tumors, those that were high grade $(n=37)$ were slightly more common than low-grade tumors $(n=30)$ by 1998 criteria, and most were grade 2 or 3 with the older (1973) grading system. When papillary tumors with any depth of invasion were considered collectively, most were high grade, regardless of the grading system utilized (1973 grade 3 tumors and 1998 high-grade tumors). With the 1973 system, one of $10(9 \%)$ grade $1-2$ tumors, nine of $37(24 \%)$ grade 2 tumors and 30 of $39(77 \%)$ grade 3 tumors were invasive. With the 1998 grading method, the majority of high-grade tumors (38 of $57 ; 66 \%$ ) were invasive, whereas, the majority of low-grade papillary urothelial carcinomas (93\%) were noninvasive. The two (6\%) 1998 low-grade tumors that were invasive only invaded into the lamina propria. Noteworthy, is the finding that the 1973 grade 2 category was composed of a group of heterogeneous tumors; by 1998 criteria, nearly one-half of these tumors were found to be high grade and the other half low grade.

Statistical analysis revealed that both grading systems (1973 and 1998) for papillary urothelial carcinomas showed a significant association with

Table 3 Distribution of papillary urothelial neoplasms by type and grade $(n=87)$

WHO 1973

\begin{tabular}{ll}
\hline $\begin{array}{l}\text { Papillary } \\
\text { urothelial } \\
\text { neoplasm }\end{array}$ & $\begin{array}{l}\text { Number } \\
\text { of cases }\end{array}$
\end{tabular}

Papillary

carcinoma

Grade 1

Grade 1-2

Grade 2

Grade 3
Papilloma

0

$$
\text { Papilloma }
$$

Low malignant potential neoplasm Papillary carcinoma Low grade High grade
WHO/ISUP 1998

\begin{tabular}{lc}
\hline $\begin{array}{l}\text { Papillary } \\
\text { urothelial } \\
\text { neoplasm }\end{array}$ & Number of cases \\
Papilloma & 0 \\
$\begin{array}{l}\text { Low malignant } \\
\text { potential neoplasm }\end{array}$ & 0 \\
$\begin{array}{l}\text { Papillary carcinoma } \\
\text { Low grade }\end{array}$ & 30 \\
$\quad$ High grade & 57 \\
\end{tabular}

WHO, World Health Organization; ${ }^{27}$ WHO/ISUP, World Health Organization/International Society of Urological Pathology. ${ }^{32}$ 
14
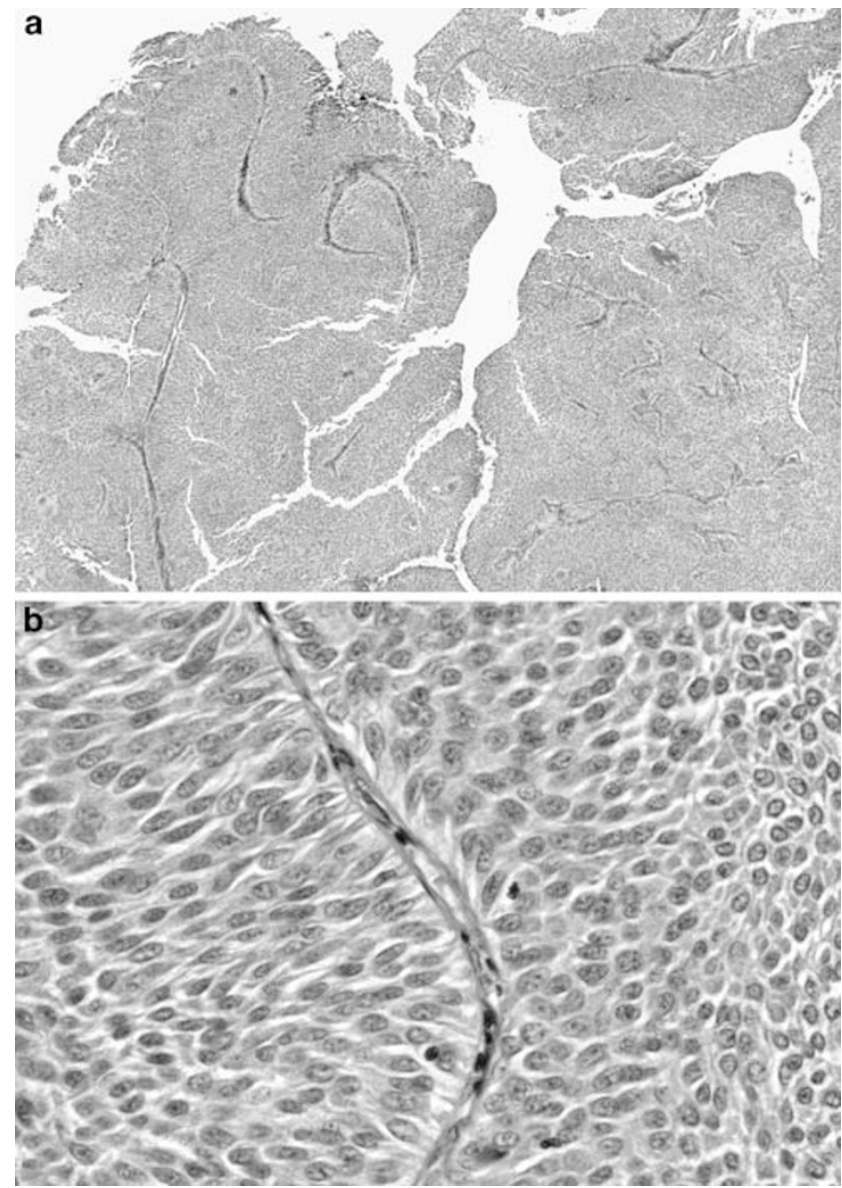

Figure 1 (a) Low-grade papillary urothelial carcinoma of the renal pelvis with fusion of papillae (hematoxylin and eosin, $\times 4$ ). (b) The tumor cells have mild nuclear pleomorphism and small nucleoli focally. The polarity of the tumor cells along the fibrovascular cores is slightly altered.

pathologic stage (Table 5). The difference in frequency of invasion between low-grade papillary carcinomas (1998) and grades $1-2$ and 2 papillary carcinomas (1973) was significant $(P=0.011)$. Additional tumor features that correlated with stage of disease included tumor necrosis with a less significant association for the presence of an inflammatory infiltrate. Squamous and glandular differentiations were present more often in deeply invasive tumors; however, the association was not statistically significant. For invasive tumors, a comparison of pT1 disease $v s \geq \mathrm{pT} 2$ disease revealed a significant association for vascular invasion $(P=0.001)$ and perineural invasion $(P=0.001)$.

Analysis of patient outcome was limited. Of the 25 patients alive with disease, 14 had metastases, six had disease in the bladder or urethra (pathology unknown), two had disease in the contralateral kidney, one had recurrence in the same kidney after partial nephrectomy and two had recurrences but the site of the disease and pathology were unknown. Performing an analysis of progression-free survival
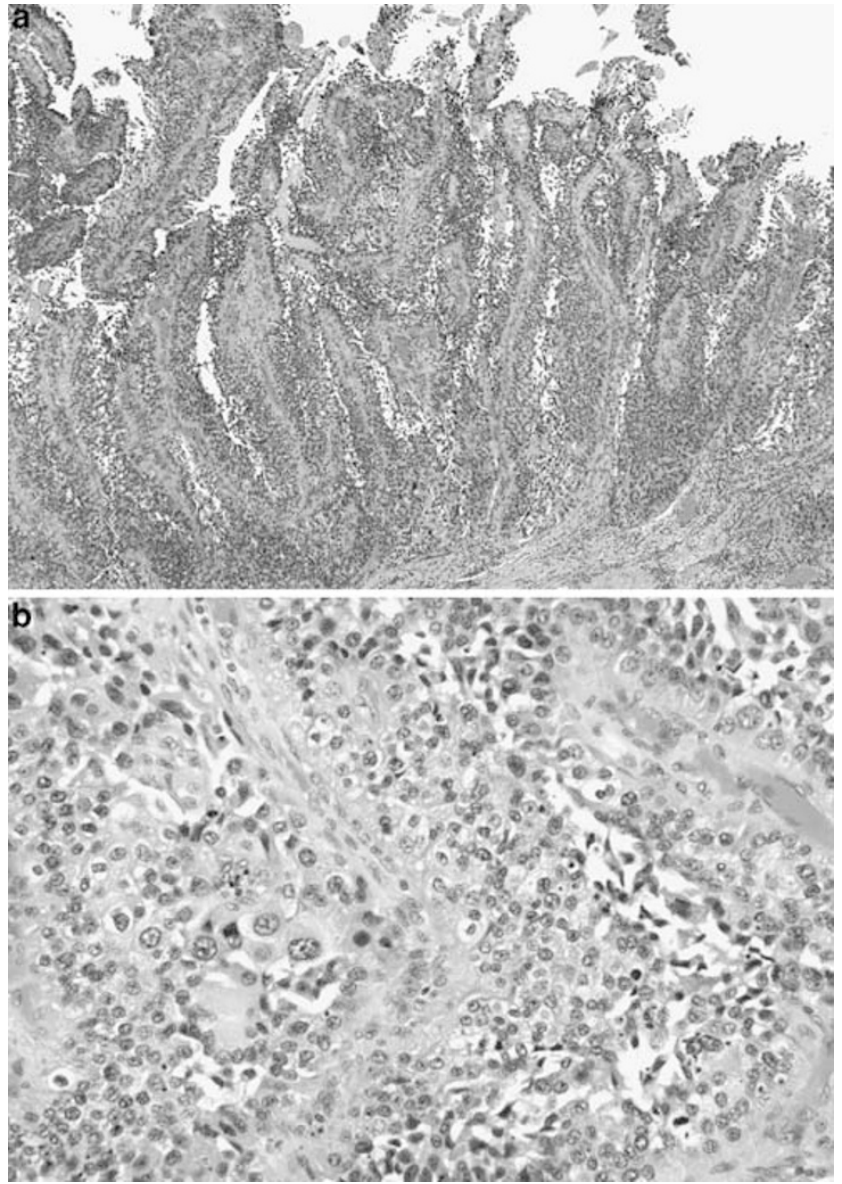

Figure 2 (a) High-grade papillary urothelial carcinoma of the renal pelvis with loss of tumor cell polarity along the fibrovascular pole, appreciable at low magnification. (b) Tumor cells with moderate to focally marked nuclear pleomorphism, coarse chromatin and scattered prominent nucleoli.

Table 4 Distribution of papillary urothelial carcinomas by grade and stage $(n=87)$

\begin{tabular}{lrrrrrr}
\hline $\begin{array}{l}\text { Stage } \\
\text { (2002AJCC) }\end{array}$ & \multicolumn{3}{c}{ WHO 1973 } & & & \multicolumn{2}{c}{ WHO/ISUP 1998 } \\
\cline { 2 - 3 } \cline { 6 - 7 } & Grade 1-2 & Grade 2 & Grade 3 & & $\begin{array}{c}\text { Low } \\
\text { grade }\end{array}$ & $\begin{array}{c}\text { High } \\
\text { grade }\end{array}$ \\
\hline PTa & 10 & 28 & 9 & & 28 & 19 \\
pT1 & 1 & 7 & 12 & & 2 & 18 \\
pT2 & 0 & 0 & 4 & & 0 & 4 \\
pT3 & 0 & 2 & 8 & & 0 & 10 \\
pT4 & 0 & 0 & 6 & & 6 \\
\hline
\end{tabular}

AJCC, American Joint Committee on Cancer Staging System; ${ }^{34}$ WHO, World Health Organization; ${ }^{27}$ WHO/ISUP, World Health Organization/ International Society of Urological Pathology. ${ }^{32}$

was problematic because the date of recurrence, pathology and site of recurrence (metastasis vs tumor elsewhere in the urothelial tract) was unavailable for many patients. Death due to disease 
Table 5 Correlation of histologic features of tumor and tumor stage

\begin{tabular}{lcc}
\hline Tumor characteristics & $\begin{array}{c}\text { Noninvasive vs } \\
\text { invasive disease } \\
\text { P-value }\end{array}$ & $\begin{array}{c}\leq p \text { T1 disease vs } \\
\geq p \text { T2 disease } \\
\text { P-value }\end{array}$ \\
\hline $\begin{array}{l}\text { Grade of papillary } \\
\text { carcinoma (WHO/ISUP) }\end{array}$ & 0.001 & 0.001 \\
$\begin{array}{l}\text { Grade of papillary } \\
\text { carcinoma (WHO) }\end{array}$ & 0.001 & 0.001 \\
$\begin{array}{l}\text { Necrosis } \\
\text { Inflammation }\end{array}$ & 0.001 & 0.001 \\
Aberrant differentiation & 0.008 & 0.019 \\
\hline
\end{tabular}

WHO, World Health Organization; ${ }^{27}$ WHO/ISUP, World Health Organization/International Society of Urological Pathology. ${ }^{32}$

was documented in only six patients, therefore, making a multivariate analysis difficult. Five of the six patients had high-grade disease in the kidney, four of which were invasive, and one patient had low grade, noninvasive disease. Of the patients who died of disease, all but one had a history of and/or developed invasive bladder carcinoma, the majority of whom (four of five patients) received chemotherapy or radiotherapy for their bladder tumor, including the one patient with low-grade disease in the kidney. Therefore, the cause of death in these patients may be attributed to the bladder tumor, and the results of the statistical analysis may more reflect the behavior of urothelial neoplasms in sites other than the kidney. In the survival analysis by univariate analysis, only two features, papillary growth pattern and increasing age, showed a trend toward influencing patient outcome; those with papillary tumors appear to have a better outcome while older age portends a worse prognosis. While there was a tendency for women to have a worse prognosis than men, the difference was not found to be statistically significant. Similarly, as so few patients died of disease, stage was not found to be a significant predictor of outcome. However, determination of the hazard ratio showed that the rate of death for patients with $\geq$ pT1 disease was 1.52 times the rate of patients with noninvasive disease (0.51, 4.56; $95 \%$ confidence interval), and the rate of death for patients with $\geq$ pT2 was 2.39 times the rate of patients with $\leq$ pT1 disease $(0.71,8.09 ; 95 \%$ confidence interval). No other pathologic feature significantly influenced survival. An assessment of tumor features that predicted metastases revealed that vascular invasion $(P=0.0002)$ and tumor necrosis $(P=0.0007)$ were found to be associated with the development of metastases.

\section{Discussion}

We applied the 1998 WHO/ISUP and 1973 WHO classification systems for urothelial neoplasms to a group of renal pelvic tumors and the two systems were compared and contrasted. In this series, no urothelial papillomas or papillary urothelial neoplasms of low malignant potential/grade 1 papillary urothelial carcinomas were present regardless of the classification system applied. Urothelial papilloma is a rare tumor in the bladder, and probably even less common in the upper tract. We have never encountered a urothelial papilloma in the upper tract (by nephrectomy or biopsy), and only rare reports of renal pelvic papillomas are published. ${ }^{10}$ Some reports of papillomas in the upper urinary tract actually appear to represent papillary urothelial neoplasms of low malignant potential. ${ }^{4}$ These latter tumors do occur in the upper tract, but may not be common; in several upper tract series, low malignant potential papillary tumors were not present or were the least common type of papillary neoplasm present. $^{4}$

Of all urothelial neoplasms of the kidney, carcinomas appear to be the most frequent, and the majority (85\%) are papillary, ${ }^{36}$ including those in this series. The prognosis of patients with these tumors has repeatedly been shown to depend on the tumor stage and grade. ${ }^{9-11,13-15,17-19,21-24}$ At nephrectomy, our study group was divided nearly equally into those with noninvasive disease and those with an invasive component (Table 2). Nielsen and Ostri $^{21}$ in their study of primary tumors of the renal pelvis had a slightly greater percentage $(56 \%)$ of noninvasive tumors. However, unlike the majority of urothelial neoplasms of the bladder which are noninvasive at presentation, ${ }^{37}$ many studies of renal pelvic tumors have shown that most patients present with invasion, with only a $3.5-34 \%$ incidence of noninvasive disease. ${ }^{14,15,19,22-24,38,39}$ In our analysis and others, ${ }^{20}$ a significantly greater number of cases demonstrated low-stage disease than highstage disease $(69 \% \leq \mathrm{pT} 1$ disease vs $31 \% \geq \mathrm{pT} 2$ disease), which closely approximates the $70 \%$ of bladder tumors which are 'superficial' (pTa, pTIS, pT1) at presentation. ${ }^{36,37}$ In two more recent series of renal pelvic tumors, Gomez et $a l^{38}$ and Olgac et $a 1^{39}$ also reported that a slightly greater number of tumors were low stage $(\leq \mathrm{pT} 1)$ than high stage. Despite the fact that investigators have used different staging systems in their series, the stage of renal pelvic neoplasms has repeatedly been shown to be a predictor of outcome; as tumor stage increases, survival decreases. In their analyses of renal urothelial neoplasms, Guinan et $a t^{23,24}$ found 5-year survival rates of $75,87,54$ and $19 \%$ for Ta/TIS, $\mathrm{T} 1 / \mathrm{T} 2, \mathrm{~T} 3$ and $\mathrm{T} 4$ disease, respectively, while 5 -year survival rates of 100, 65, 34 and $0 \%$ for stages A, B, C and D, respectively, have been reported by Nocks et al. ${ }^{18}$

The newer (1998) classification/grading system reveals that the majority of renal pelvic papillary urothelial carcinomas are high grade, and demonstrates, not unexpectedly, that invasion is more common with these tumors (Tables 3 and 4). Only $34 \%$ of renal pelvic papillary carcinomas were low 
grade; the majority (93\%) of these tumors were noninvasive, and when invasive, infiltrated only into the lamina propria. In similar studies assessing the 1998 system for renal pelvic carcinomas, Gomez et $a l^{38}$ and Olgac et $a l^{39}$ reported that most patients presented with high-grade disease, with only 23 and $29 \%$ of their patients, respectively, having low-grade disease. When the 1973 system was applied to the tumors in the current series, most of the papillary tumors were grades 2 and 3 tumors, and the majority of tumors that demonstrated invasion were grade 3 tumors (Tables 3 and 4). That most invasive papillary carcinomas are high grade, as defined by either system, is not an unexpected finding, and is a feature the 1998 and 1973 systems share. What they do not have in common is an 'intermediate' grade 2 category, which is a feature of the 1973 system. A grading system for papillary carcinomas which is three-tiered with an 'intermediate' grade 2 category may not provide particularly useful information, as the significance of grade 2 papillary carcinomas is unclear. This group of tumors, as seen in the current series, is composed of a heterogeneous population of low- and high-grade tumors. This is demonstrated by the fact that $10 \mathrm{pTa}$, six pT1 and both pT3 grade 2 tumors were diagnosed as high grade by the 1998 criteria, while the remainder of the grade 2 tumors were low grade. An advantage of the 1998 WHO/ ISUP two-tiered grading system for papillary carcinomas is that it eliminates the categorization of tumors into an 'intermediate' group, thereby assisting to eliminate the greater heterogeneity inherent to grading schemes with more grade categories. Additionally, using the 1998 system allows for the identification of a group of cancers, namely lowgrade papillary carcinomas, that is associated with a very low frequency of invasion and when invasive, were found to invade no further than into the lamina propria in this study. Rarely, these low-grade tumors may be of higher stage $(\geq \mathrm{pT} 2){ }^{38}$ Use of the 1973 grading system, in this series, did not appear to as reliably predict for a group of tumors that have a low risk of invasion.

Despite the difference in number of grading categories between the 1973 and 1998 systems, in this analysis, the grade of papillary urothelial carcinomas was shown to be associated with pathologic stage with both grading methods (Table 5). Furthermore, a variety of other, different grading systems have been studied previously, and all showed that the grade of renal pelvic tumors correlates with survival. In their assessment of urothelial neoplasms of the kidney, Davis et a $1^{19}$ reported 5-year survival rates of 100,67 and $5 \%$ for grades 1, 2 and 3 tumors, respectively, while Nocks et $a l^{18}$ found 5-year survival rates of 100, 90 and $23 \%$ for grades 1, 2 and 3 tumors. The patients in the series by Rubenstein et $a l^{17}$ faired much worse with 5 -year survival rates of $80,33,11$ and $0 \%$ for grades 1-4 tumors, respectively. In these studies, the rates of survival for grade 2 tumors are drastically different (67 vs 90 vs 33\%), which lends support to the contention that grade 2 tumors are a cytologically heterogeneous group.

Therefore, if both the 1973 and 1998 classification schemes are significantly associated with tumor stage, does the newer (1998) classification scheme, when applied specifically to renal urothelial neoplasms, truly provide more meaningful information to the pathologist and urologist? The $1998 \mathrm{WHO} /$ ISUP classification scheme aimed to (1) provide greater uniformity for classifying urothelial lesions, especially papillary tumors and (2) it also intended to provide a method which more accurately classifies these papillary tumors according to their biologic behavior. The first objective can certainly be met regardless of the site of tumor as long as there is consistency among pathologists about using the system. The second objective is important because it assists in determining the likelihood of tumor recurrence and progression and, therefore, assists in planning future patient management. For tumors that occur in the bladder, the use of a system that better characterizes a tumor's biologic behavior is prudent, as initial therapy does not usually involve radical cystectomy. Unlike bladder tumors, however, in the upper tract neither the grade nor stage of renal urothelial neoplasms is assessed routinely prior to definitive therapy. These data have not traditionally played a significant role in determining initial therapy, which, in most cases, is radical nephroureterectomy. In the kidney, use of grading nomenclature, which, as accurately as possible, relays to the urologist/oncologist the likely biologic progression is unquestionably useful. Tumor stage will do that as well. The issue of tumor recurrence in the renal pelvic-calyceal system is not a concern when the entire organ is removed. If, however, treatment of these renal tumors moves in the direction of nephron-sparing therapy and begins to more closely approximate therapy for bladder tumors, then use of the newer (1998) system may be more advantageous than the 1973 system. Some investigators have suggested that select patients, in particular those with low grade, low-stage (pT1 or less) disease and a normal contralateral kidney, could be managed with nephron-sparing procedures because they have very good outcomes. ${ }^{4,40-43}$ The 1998 grading system may be quite useful in these circumstances, as it appears to more clearly separate low- from high-grade tumors, and shows that lowgrade tumors are associated with a low risk of invasion.

In this series, use of the 1998 WHO/ISUP classification system for urothelial neoplasms revealed that urothelial papillomas and papillary urothelial neoplasms of low malignant potential are uncommon tumors in the kidney. Most renal pelvic neoplasms are papillary carcinomas and the majority of patients presented with 'superficial' disease $(\leq \mathrm{pT} 1)$. Most papillary urothelial carcinomas of the renal pelvis are high grade and are more 
often invasive, and more often deeply invasive, than low-grade tumors. Low-grade papillary carcinomas account for only $34 \%$ of renal pelvic carcinomas, and the majority of these low-grade carcinomas are noninvasive. As such, the 1998 system selects for a group of tumors in which a low risk of invasion can be predicted. The criteria established for grading papillary carcinomas with the 1998 system eliminates the ambiguity of the heterogeneous 1973 WHO grade 2 category. Uniformity in terminology for urothelial neoplasms is necessary, regardless of the site of origin. Whether the new two-tiered system for grading papillary urothelial carcinomas offered by the 1998 classification scheme will prove to be more clinically advantageous for urothelial neoplasms of the kidney by more definitively segregating good and poor prognostic groups than the 1973 system requires further investigation.

\section{Acknowledgement}

The authors wish to thank Jeffrey Goldsmith, MD, for his assistance with photography.

\section{References}

1 Murphy WM, Beckwith JB, Farrow GM. Tumors of the kidney, bladder, and related urinary structures, Fascicle 11, 3rd Series. In: Rosai J, Sobin LH (eds). Atlas of Tumor Pathology. Armed Forces Institute of Pathology: Washington, DC, 1994, pp 193-198, 313-321.

2 Dudak SC, Soloway MS, Neulander EZ. Management of upper tract transitional cell carcinoma: surgical management. In: Vogelzang NJ, Scardino PT, Shipley WU, Coffey DS (eds). Comprehensive Textbook of Genitourinary Oncology. Lippincott Williams \& Wilkins: Philadelphia, 2000, pp 376-383.

3 Huffman JL. Management of upper tract transitional cell carcinomas: endoscopic management. In: Vogelzang NJ, Scardino PT, Shipley WU, Coffey DS (eds). Comprehensive Textbook of Genitourinary Oncology. Lippincott Williams \& Wilkins: Philadelphia, 2000, pp 367-376.

4 Genega EM, Porter CR. Urothelial neoplasms of the kidney and ureter. An epidemiologic, pathologic and clinical review. Am J Clin Pathol 2002;117(Suppl 1): S36-S48.

5 Jemal A, Murray T, Samuels A, et al. Cancer statistics, 2003. CA Cancer J Clin 2003;53:5-26.

6 Lee S-H, Lin JS-N, Tzai T-S, et al. Prognostic factors of primary transitional cell carcinoma of the upper urinary tract. Eur Urol 1996;29:266-271.

7 McDonald JR, Priestly JT. Carcinoma of renal pelvishistopathologic study of 75 cases with special reference to prognosis. J Urol 1944;51:245-258.

8 Taylor WN. Tumors of the renal pelvis. J Urol 1959; 82:452-458.

9 Grace DA, Taylor WN, Taylor JN, et al. Carcinoma of the renal pelvis: a 15-year review. J Urol 1968;98: 566-569.

10 Grabstald H, Whitmore WF, Melamed MR. Renal pelvic tumors. JAMA 1971;218:845-854.
11 Williams CB, Mitchell JP. Carcinoma of the renal pelvis: a review of 43 cases. Br J Urol 1973;45:370-376.

12 Say CC, Hori JM. Transitional cell carcinoma of the renal pelvis: experience from 1940-1972 and literature review. J Urol 1974;112:438-442.

13 Wagle DG, Moore RH, Murphy GP. Primary carcinoma of the renal pelvis. Cancer 1974;33:1642-1648.

14 Cummings KB, Correa RJ, Gibbons RP, et al. Renal pelvic tumors. J Urol 1975;113:158-162.

15 Johansson S, Angervall L, Bengtsson U, et al. A clinicopathologic and prognostic study of epithelial tumors of the renal pelvis. Cancer 1976;37:1376-1383.

16 Leong CH, Lim TK, Wong KK, et al. Carcinoma of the renal pelvis: an analysis of the diagnostic problems in 23 cases. Br J Surg 1976;63:102-106.

17 Rubenstein MA, Walz BJ, Bucy JG. Transitional cell carcinoma of the kidney: 25-year experience. J Urol 1978;119:594-597.

18 Nocks BN, Heney NM, Daly JJ, et al. Transitional cell carcinoma of the renal pelvis. Urology 1982;14: 472-477.

19 Davis BW, Hough AJ, Gardner WA. Renal pelvic carcinoma: morphological correlates of metastatic behavior. J Urol 1987;137:857-861.

20 Blute ML, Tsushima K, Farrow GM, et al. Transitional cell carcinoma of the renal pelvis: nuclear deoxyribonucleic acid ploidy studied by flow cytometry. J Urol 1988;140:944-949.

21 Nielsen K, Ostri P. Primary tumors of the renal pelvis: evaluation of clinical and pathological features in a consecutive series of 10 years. J Urol 1988;140:19-21.

22 Vahlensieck W, Sommerkamp H. Therapy and prognosis of carcinoma of the renal pelvis. Eur Urol 1989;16:286-290.

23 Guinan P, Volgelzang NJ, Randazzo R, et al. Renal pelvic transitional cell carcinoma. The role of the kidney in tumor-node-metastasis staging. Cancer 1992; 69:1773-1775.

24 Guinan P, Vogelzang NJ, Randazzo R, et al. Renal pelvic cancer: a review of 611 patients treated in Illinois 1975-1985. Urology 1992;40:393-399.

25 Ash JE. Epithelial tumors of the bladder. J Urol 1940; 44:135-145.

26 Bergkvist A, Ljungqvist A, Moberger G. Classification of bladder tumors based on the cellular pattern: preliminary report of a clinical-pathological study of 300 cases with a minimum follow-up of eight years. Acta Chir Scand 1965;130:371-378.

27 Mostofi FK, Sorbin LH, Torloni H. Histological typing of urinary bladder tumors. International histological classification of tumors. No. 10. World Health Organization, Geneva, Switzerland, 1973.

28 Koss LG. Tumors of the urinary bladder, Fascicle 11, 2nd Series. In: Firminger HI (ed). Atlas of Tumor Pathology. Armed Forces Institute of Pathology, Washington, DC, 1974, pp 9-38.

29 Bennington JL, Beckwith JB. Tumors of the kidney, renal pelvis and ureter, Fascicle 12, 2nd Series. In: Firminger HI (ed). Atlas of Tumor Pathology. Armed Forces Institute of Pathology, Washington, DC, 1975 , pp 243-311.

30 Pauwels RPE, Schapers RFM, Smeets AWGB, et al. Grading in superficial bladder cancer. (1) morphological criteria. Br J Urol 1988;61:129-134.

31 Schapers RFM, Pauwels RPE, Wijnen JThM, et al. A simplified grading method of transitional cell carcinoma of the urinary bladder: reproducibility, clinical 
significance and comparison with other prognostic parameters. J Urol 1994;73:625-631.

32 Epstein JI, Amin MB, Reuter VE, and the Bladder Consensus Conference Committee. The World Health Organization/International Society of Urological Pathology consensus classification of urothelial (transitional cell) neoplasms of the urinary bladder. Am J Surg Pathol 1998;22:1435-1448.

33 Mostofi FK, Davis CJ, Sesterhenn I. Histological Typing of Urinary Bladder Tumors, 2nd ed. Springer: Berlin, 1999.

34 Eble JN, Sauter G, Epstein JI, et al. Pathology and genetics. Tumours of the urinary system and male genital organs. World Health Organization Classification of Tumours, 2004.

35 Thompson IM, Andriole GL, Blumenstein B, et al. Renal pelvis and ureter. In: Greene FL, Page DL, Fleming ID, Fritz AG, Balch CM, Haller DG, Morrow M (American Joint Committee on Cancer) (eds). AJCC Cancer Staging Manual, 6th edn. Springer-Verlag: New York, 2002, pp 329-331.

36 Sagalowsky AI, Jarrett TW. Management of urothelial tumors of the renal pelvis and ureter. In: Walsh PC, Retik AB, Vaughan ED, Wein AJ (eds). Campbell's Urology. Saunders: Philadelphia, 2002, pp 2845-2875.
37 Malkowicz SB. Management of superficial bladder cancer. In: Walsh PC, Retik AB, Vaughan ED, Wein AJ (eds). Campbell's Urology. Saunders: Philadelphia, 2002, pp 2785-2802.

38 Gomez JA, Tamboli P, Slaton JW, et al. Urothelial carcinoma (UC) of the upper urinary tract: a clinicopathologic study of 70 cases from 1985-2000. Mod Pathol 2001;14:109A (abstract).

39 Olgac S, Dalbagni G, Reuter VE. Urothelial carcinoma of the renal pelvis. Mod Path 2003;16:164A (abstract).

40 Grasso M, Fraiman M, Levine M. Ureteropyeloscopic diagnosis and treatment of upper urinary tract urothelial malignancies. Urology 1999;54:240-246.

41 Chen GL, Bagley DH. Ureteroscopic management of upper tract transitional cell carcinoma in patients with a normal contralateral kidneys. J Urol 2000;164: 1173-1176.

42 Jabbour ME, Smith AD. Primary cutaneous approach to upper urinary tract transitional cell carcinoma. Urol Clin N Am 2000;27:739-750.

43 Elliot DS, Segura JW, Lightner D, et al. Is neproureterectomy necessary in all cases of upper tract transitional cell carcinoma? Long-term results of conservative endourologic management of upper tract transitional cell carcinomas in individuals with a normal contralateral kidney. Urology 2001;58:174-178. 